УДК 811.133.1'373

\title{
О.А. Кузьмина
}

\section{К ВОПРОСУ ОБ ОПИСАНИИ АРГОТОГРАФИЧЕСКИХ ИСТОЧНИКОВ (НА МАТЕРИАЛЕ НОВЕЙШЕГО СИНХРОНИЧЕСКОГО СРЕЗА ФРАНЦУЗСКОГО МОЛОДЁЖНОГО АРГО)}

Статья посвящена словарной работе французского журналиста Венсана Монгайара, в которой инвентаризированы единицы французского молодёжного арго. Цель статьи - анализ тематических разделов обозначенного арготографического труда, сгруппированных исходя как из приёмов словопреобразования, так и систематизации аргоаттрактивных концептов. Лексикографическое издание, созданное на материале новейшего синхронического среза специфического вокабуляра, представлено по нижеследующим критериям: объём лексического фонда, источники и механизмы словообразования, семантические доминанты, синонимические ряды и метафорика. В ходе проведённого исследования выявлены системные способы арготического словотворчества. При этом подтверждается частотность применения такого специфического словообразовательного средства, как верлан: арготизмы, образованные посредством верланизации, включены во все представленные в работе семантические макрополя. Из неспецифических механизмов пополнения арготического фонда следует прежде всего назвать метафорику. Отдельное внимание уделено описанию заимствований. В работе приводятся многочисленные примеры с переводом на русский язык.

Ключевые слова: французское молодёжное арго, механизмы словообразования, верлан, семантическая доминанта, иноязычные заимствования, синонимические ряды.

DOI: $10.35634 / 2412-9534-2020-30-5-847-852$

Полиаспектный анализ любого субъязыка начинается с изучения результатов его словарной фиксации. «Минуя лексикографию, арготолог не сможет делать какие-либо выводы и обобщения» [1. С. 218]. Характеристика арготографических источников, по мнению российского арготолога Т.И. Ретинской, является неотъемлемой и одной из самых важных составляющих алгоритма сбора языкового материала для дальнейшего исследования. На первом этапе исследования французского молодёжного арго мы обратились к многочисленным словарным работам, одну из которых - словарь Le petit livre de la tchatche Венсана Монгайара - представим в настоящей статье. Лексикографический труд выпущен парижским издательством First Éditions в 2013 г. Название словарной работы содержит молодёжный арготизм la tchatche 'болтовня': слово зафиксировано в словаре Жан-Пьера Гудайе Comment tu tchatches! 1998 г. издания [6. С. 231]. Особый интерес представляет вступительная статья автора, в которой он излагает свое отношение к арготирующим и оценивает влияние молодёжного субъязыка на национальный язык и культуру. В. Монгайар, журналист французской ежедневной газеты Le Parisien, уверен, что французское молодёжное арго начала XXI в. представляет собой сочетание лексем, свойственных традиционному арго, заимствований из арабского, африканских, цыганских языков, а также субъязыка американских рэперов. По его мнению, существует общий репертуар слов, который известен молодым людям в разных уголках страны, а также арготическая лексика, свойственная отдельному языковому коллективу. Автор считает, что язык молодёжи ни в коем случае не обедняет старый добрый язык Мольера, а наоборот, он обогащает его и делает более живым [8. С. 7].

Для описания словаря арготической лексики существует полная пятиаспектная схема, разработанная Э.М. Береговской для изучения французских профессиональных арго, которая включает следующие пункты:

1. Объём лексического фонда.

2. Источники и механизмы словообразования.

3. Семантические доминанты.

4. Синонимика.

5. Метафорика.

Эти критерии были неоднократно апробированы самим автором при выявлении характерных черт различных профессиональных говоров, а также её учениками в ходе развёрнутого анализа арго французских журналистов, виноградарей и виноделов, фермеров. Т.И. Ретинская предлагает более детально проанализировать образность арго той или иной референтной группы, именуя заключитель- 
ный компонент единой схемы характеристики арготического вокабуляра «тропологическим пространством» [2. С. 166]. Мы не в полной мере будем следовать вышеобозначенным пунктам исходя из специфики рассматриваемого словаря, поскольку лексемы систематизированы не в алфавитном порядке, а по тематическому принципу. Объём зафиксированного словарного фонда составляет около 300 арготических единиц, при инвентаризации которых учитывались как источники и механизмы арготического словопреобразования, так и семантические доминанты:

1. Les mots du verlan 'Слова, образованные при помощи верлана';

2. Les mots venus d'ailleurs 'Заимствованные слова';

3. Les mots de Marseille et de Lyon 'Арго подростков Марселя и Лиона';

4. Les mots du quotidien 'Слова из повседневной жизни';

5. Les mots qui font rire 'Слова, которые заставляют смеяться';

6. Les mots du trafic 'Слова из обихода нелегальных торговцев оружием и наркотиками';

7. Les mots des rappeurs 'Арго рэперов'.

Два вышеназванных раздела имеют подразделы. Tак, Les mots venus d'ailleurs включает в себя Nés au Bled 'Слова, рождённые на малой родине', Originaires d'Afrique Noire 'Слова родом из Чёрной Африки', Made in USA 'Сделано в США'. В разделе Les mots du quotidien собраны слова и выражения, используемые в повседневной жизни, посредством которых описывают условия проживания, облик зданий, внешний вид и одежду, приветствия и обращения к приятелям, парням и девушкам и другие: Bienvenue dans mon quartier 'Добро пожаловать в мой район'; T'as le look, coco 'Классно выглядишь, крошка'; Les potes, c'est la famille 'Друзья - это семья'; La cité, ton univers impitoyable 'Жестокий мир города'; Guerre des sexes 'Война полов'; La voiture, mon amour 'Любовь моя, автомобиль'; Accros aux écrans 'Любители смартфонов'.

Словарная статья содержит характеристику арготизма, включающую этимологию, лингвистический комментарий, словообразовательный механизм, примеры употребления в контексте, в котором анализируемое слово сопоставляется с разнообразными арготическими лексемами, включая синонимы.

Первый раздел 'Les mots du verlan' выделен по способу образования арготической лексики. Верлан (verlan от французского наречия (à) l'envers 'наоборот') является одним из самых распространённых способов образования молодёжных арготизмов наряду с заимствованиями и метафорикой. Этот приём относится к специфическим словообразовательным механизмам по схеме, представленной Т. И. Ретинской [4. С. 8]. Он заключается в перестановке звуков и слогов исходного слова, например, dingue 'сумасшедший' превращается в gueudin, quartier 'квартал' в tiékar. В. Монгайар говорит о том, что к использованию верлана прибегали уже в Средние века: в XII в. в известной легенде о Тристане и Изольде, героя иногда называли Тантрис (Tantris < Tristan) [8. С. 19].

Верланизированные слова не всегда подразумевают то же, что исходное слово. Так, méchant 'злой' становится chanmé и означает прямо противоположное: 'замечательный', 'гениальный'. Нередки случаи, когда у слова появляются два автономных значения, и оба они имеют мало общего со значением лексемы-источника. В качестве примера процитируем прилагательное sec 'cухой' > keuss 1) 'худой'; 2) 'скучный'. Этот арготизм может характеризовать как человека, так и историю, рассказ, вечеринку.

Верланизации подвергаются слова и словосочетания из литературного французского, английского, западноафриканских языков, а также лексемы из общего арго:

- англ. hard ‘твердый '> dar 1) 'тяжело', 'трудно'; 2) ‘классно', ‘здорово';

- англ. speed > deuspi 'быстро';

- волоф toubab 'европеец' > babtou 'белокожий житель Франции';

- общее арго bled 'сельская местность в Северной Африке', 'захолустье', 'дыра' > blédard > darblé 'выходец из стран Магриба';

- общее арго lascar > scarlette 'девушка из пригорода';

- общее арго caillasse > yaska 'деньги';

- общее арго carotter > rotca 'воровать'.

Арготизмы, построенные при помощи верлана, по праву включены в первый раздел словаря, поскольку именно этот словообразовательный механизм чаще других используется для пополнения молодёжного вокабуляра. Такое массивное употребление этого вида кодирования Ж.-П. Гудайе объясняет тем, что молодёжь демонстрирует свое неприятие общества, которое пытается её притеснить. При помощи этого механизма представители поколения Z (рожденные в 90-х гг.) стараются не только 
закодировать свою речь (криптолалическая функция), но и подчеркнуть свою идентичность (идентифицирующая функция) по отношению к тем, кто не с ними [7. С. 145]. Как только верланизированное слово становится известно иным носителям национального языка, оно может быть неоднократно подвергнуто реверланизации [7. С. 144].

Другие шесть разделов рассматриваемой нами словарной работы также содержат значительное количество лексем, образованных путем метатезы. Прежде всего упомянем лексему из арабского языка avoir le seum 1) ‘нервничать’; 2) ‘ненавидеть': J'ai le pur gros seum, mon keum (mec), il a chiné (dragué) ma reus trop cheum (moche). В процитированной фразе использованы ещё три лексические единицы, построенные с помощью обозначенного приёма: keum < mec 'парень', 'друг', reus < soeur 'сестра', cheum < moche 'страшная'.

В подразделе Les potes, c'est la famille верланизированным оказались все компоненты словосочетания fumer la moquette 'бредить', ‘болтать глупости' > mefu la ketmo.

Отметим при этом, что в словаре В. Монгайара верланизированные лексемы включены в контекст, эксплицирующий значения иных арготизмов: Je suis à oilpé (à poil), j’ai plus une roupie pour m'acheter des sketbas (baskets) 'Голяк, у меня нет денег, чтобы купить себе кроссы (кроссовки)' (раздел Les mots qui font rire).

В Les mots du trafic инвентаризируются нижеследующие верланизмы:

- peufra 'гашиш хорошего качества' < frappe 'удар';

- leurdis < dealer 'дилер';

- reurti < tireur 'вор', 'специалист по краже смартфонов и золота': Le reurti de 12 ans, il a péta (peta < taper 'требовать') des portables dans le train 'Двенадцатилетний воришка стырил смартфоны в поезде';

- zarbi < bizarre 'странный';

- zermi < misère 'нищета';

- bébar < barber 'воровать';

- zeudou $<$ douze 'двенадцать граммов наркотика, чаще всего продаваемое потребителю'.

Отдельное внимание уделено лексеме brelic: в данном случае речь идёт о произвольном верлане от слова calibre, обозначающего 'пистолет' (здесь мы наблюдаем метонимию, а точнее разновидность метонимии - синекдоху, когда оружие именуют по одной из его характеристик).

Небезынтересно упомянуть, что автор словаря живёт и трудится в Париже, а именно здесь, в окрестностях и пригородах столицы данный словообразовательный приём популярен, как отмечает Ж.-П. Гудайе в статье La langue des cités, впервые опубликованной в Communication et Langages в 1997 г. [7. С. 55].

Второй раздел Les mots venus d'ailleurs объединил в себе слова, заимствованные из арабского, южноафриканских языков, американского варианта английского. По словам В. Монгайара, в игру вступают родные языки. Поскольку значительная часть молодых людей городских окраин является детьми иммигрантов, они активно пополняют свой вокабуляр словами, происходящими из языка, на котором говорят их родители и многочисленные родственники, по-прежнему проживающие в странах Магриба и Центральной Африки. У каждого заимствования своя небезынтересная история. Так, девушку 'jeune fille', женщину 'femme' называют zouz; эта лексема в Тунисе означает 'два', и именно это слово дало название первому сайту знакомств в стране. Арготизм арабского происхождения shrab 'вино', 'алкоголь' взято на вооружение завсегдатаями молодёжных вечеринок. При помощи основосложения schrab и bouille 'морда', 'рожа', а также суффикса, имеющего пейоративное значение -ard получаем un schrabouillard 'пьяница', 'алкаш'.

Выражение en soum-soum 'втайне', 'украдкой' пришло из Сенегала, где так назывался незаконно изготовленный алкогольный напиток на основе ореха кешью. Заимствованное из Мали и Котд’Ивуара выражение y'a dra близко по значению к русскому словосочетанию 'запахло жареным', когда речь идёт о предполагаемых проблемах.

Молодёжь из пригорода активно перенимает слова из популярных песен американских исполнителей хип-хопа, которые стали мультимиллионерами благодаря своим хитам, и поэтому являются примером для подражания в глазах подростков.

В третий раздел автор отдельно выносит заимствования не из других языков, а из городов Марселя и Лиона, которые являются соответственно вторым и третьим городом по численности населения во Франции. В Лионе одной только учащейся молодёжи насчитывается около 90 тысяч человек. 
Оба города выделяются не только футбольными победами, но и особенностями молодёжного субъязыка. Так, в северных кварталах Марселя речь молодёжи особенно контрастирует с литературным французским языком [8. С.45].

В этом городе молодые люди говорят c'est dégaine вместо c'est joli, c'est beau 'это красиво', когда речь идёт о внешнем виде, об одежде. Degun, похожее по звучанию на слово из предыдущего выражения, означает 'никто': vous ne devez rien à degun 'вы никому ничего не должны'. C'est rhéné выражение-загадка, так как непонятно происхождение слова rhéné 'никудышный', 'плохой', возможно, оно образовалось от Rennais 'футболисты города Ренн' после их ошеломляющего разгрома на стадионе Велодром. Если в речи звучит engatse, значит, у собеседника есть 'проблема', s'engatser синонимично s'énerver 'нервничать', а l'engatsé - 'человек, потерявший контроль над собой'. И наконец, engatser quelqu'un означает 'вынести кому-либо мозг'. Процитируем еще несколько арготизмов, свойственных марсельской молодежи:

- garofeur 'обманщик' < garofer 'обманывать';

- payot 1) ‘марсельский болван', 'тупица'; 2) ‘молодой человек не из этой местности', который не разделяет ценности местной молодёжи, скорее всего выходец из более обеспеченных слоёв населения;

- payotte - 'девушка', вероятнее всего, слово происходит от цыганского рауо 'не цыган';

- tarpin - 'много', 'очень', 'слишком' (средиземноморский вариант общефранцузского наречия trop, grave).

Следует подчеркнуть, что ни одно из перечисленных слов не зафиксировано на сегодняшний день в словаре французского общенационального языка.

Говоря о молодых людях Лиона, В. Монгайар образно отмечает их креативность и именует посредством антропонима «les Bocuse de la tchatche» [8. С. 53] (Поль Бокюз - всемирно известный французский шеф-повар и ресторатор). В устах лионской молодёжи новую жизнь приобрели устаревшие арготические лексемы. Так, заимствованный из цыганского языка глагол balnave 'лгать', 'обманывать' посредством конверсии приобрел значение 'никакой', 'дерьмовый'. В словаре Стефана Риберо, который мы анализировали ранее, это лексема имела значение 'обманывать' [3. С. 127]. Отметим, что многие заимствования из цыганских языков пополнили словарь французской молодёжи: chafrave 'работать', guenave 'танцевать', pestrave 'платить', rodave 'следить', se pagave 'падать', se courave 'драться', graillave 'есть', pillave 'напиваться', nachave 'сбегать' и многие другие. Эти глаголы не нужно спрягать, что, несомненно, повышает привлекательность их употребления в речи.

Упомянем интересный случай метафоричного переноса: je rouille (букв. 'я ржавею') означает 'я скучаю' и пример его употребления во фразе: Je rouille, trop balnave son cours sur l'autre trépané de Tonpla (Platon), je préfère encore zoner le quartier 'Можно умереть от скуки на этом уроке про очередного сумасшедшего Платона, лучше я прошвырнусь по кварталу'. Ещё один пример метафоры, построенной на переносе животное - человек: родителей подростки Лиона называют yorks по названию йоркширской породы собак, так как те обычно ворчат, «лают» на своих детей, заставляя лентяев чтолибо сделать. Появившись в Лионе из цыганского языка romani арготизм pélo 'парень', 'чувак' быстро распространилось в городе, затем в соседних городах Франции и используется в значении 'мой парень', 'мой молодой человек'.

Последний раздел словаря интересен тем, что в нём рассматриваются слова из песен рэперов; они, как никто лучше знакомят слушателей с молодёжными арготизмами, которыми пестрят их речитативы. В последующем именно эти единицы пополняют арготический фонд городской молодёжи. В их песнях оживают лексемы из старого арго, как, например, blaze 'прозвище', 'погоняло'. Зачастую арготическая лексика имеет пейоративное значение, поэтому удивительно наблюдать обратную картину в следующем примере: слово crouille использовалось несколько десятилетий назад в традиционном арго как расистское ругательство, которым называли жителя Магриба, а сейчас оно используется в значении 'брат', 'друг'. Произошло так называемое возвращение к источнику: этимологически слово восходит к арабскому khouya 'мой брат'. В своём новом значении оно звучит в песнях французского рэпера сенегальского происхождения Sefyu (верлан от настоящего имени Youssef). Зачастую рэперы включают в тексты своих песен неологизмы, которые потом активно используются подростками. Так, В. Монгайар в словарной статье 'dans ma werss' говорит о том, что это 'чистая выдумка рэпера Rohf' и означает 'dans mon univers' [8. С. 150]. На наш взгляд, здесь речь может идти о таком приёме, как афереза, то есть опускание слога в начале слова. 
Проанализировав все разделы словаря, мы обнаружили в каждом из них арготизмы, которыми обозначают девушку, женщину. Именно вокруг этого денотата выстроились самые длинные синонимические ряды, в которые входят от 16 до 20 лексем:

belle gosse - beubon - bombax - bombe - frappe - fusée - gazelle - go - gorette - habibette - hiel mururoa - papiche - pétard - puefra - turbo diesel - zabour 'красивая девушка';

batonnet - carte bleue - chou - cuisse - cure-dent - djogo - fax - findus - gadji - gavali - meuf paille - planche - rakli-rate - schneck - skeud - sque - tchaï-zesse 'женщина';

biatch - crasseuse - FDP - khanzette - michto $<$ michtonneuse - neuché $<$ chienne - starfuckeuse tagasse - tainpu $<$ putain - tainp - tapin - taspé < petasse - tass - tatass - tcheubi < bitch - tschoin zoulette 'женщина лёгкого поведения'.

Известно, что арго отличается довольно быстрым ростом синонимических рядов. По результатам исследований, проведённых Е. Н. Саблиной, подтвердилось, что развитие и пополнение арготических рядов синонимов происходит за счет метафоризации и метонимизации [2. С. 7]. Проиллюстрируем наиболее яркие примеры метафорических переносов из анализируемого словаря:

- mettre une disquette (букв. 'вставить дискету') - 'обмануть человека', 'ввести в заблуждение'. Чтобы оценить метафоричность фразы, необходимо вспомнить то время, когда в старых системных блоках был дисковод, а в новых он не предусмотрен, и такой предмет, как дискета, уже вышел из употребления. Существуют и варианты этого словосочетания: mettre une clé USB, une carotte, une biture, une courgette, un chou.

- charbonneur < aller au charbon 'ходить на работу' (метафора построена на лексеме le charbon 'уголь') 'продавец наркотиков';

- skeud < disque 'очень худая девушка с плоской грудью';

- pétard 1) симпатичная девушка; 2) молодой человек (ни 'петарда', ни 'хлопушка', ни даже 'шухер' (значения, вышедшие из употребления).

Таким образом, анализ арготического фонда словаря В. Монгайара выявил некоторые особенности французского молодёжного субъязыка на данном этапе его существования, которые являются важными для понимания происходящих в нём процессов. Отметим необходимость дальнейшего сопоставления синхронических срезов на основе новейших арготографических источников для выявления системных и спорадических механизмов арготического словотворчества и исследования витальности лексем французского молодёжного арго.

\section{СПИСОК ИСТОЧНИКОВ И ЛИТЕРАТУРЫ}

1. Береговская Э.М. О современном состоянии русской социодиалектной лексикографии // Восьмые Поливановские чтения. Ч. 3. Слово в тексте. Лексикография как источник информации для лингвистических исследований. Смоленск: СмолГУ, 2007. С. 215-222.

2. Береговская Э.М. Французская арготология в России: коллективная монография / Отв. ред. Э.М. Береговская; Смол. гос. ун-т. Смоленск: Изд-во СмолГУ, 2011.348 с.

3. Кузьмина О.А. Активные процессы в современном французском молодёжном арго // Проблемы лингвистики, методики обучения иностранным языкам и литературоведения в свете межкультурной коммуникации. Материалы III Международной научно-практической конференции. Орел: ОГУ имени И.С. Тургенева, 2018. C. 124-128.

4. Ретинская Т.И. Источники и механизмы формирования французского студенческого арго: автореф. дис. ... канд. филол. наук. М., 2004.

5. Ретинская Т.И. Социолингвистический и функционально-стилистический анализ французских профессиональных арго: монография. Орел: Изд-во ОГУ, 2011. 284 с.

6. Goudaillier J.-P. Comment tu tchatches ! Dictionnaire du français contemporain des cités - préf. Claude Hagège. Paris: Maisonneuve et Larose, 1998. 263 p.

7. Goudaillier J.-P. La langue des cités // 25 ans d'écrits lexicographiques et argotologiques Hommage à Jean-Pierre Goudaillier pour son 65 anniversaire. Redaction Andrzej Napieralski. Lodz, 2014. 274 p.

8. Mongaillard V. Le petit livre de la tchatche. Décodeur de l'argot des cités. Paris. Editions First-Gründ, 2013.165 p.

Поступила в редакцию 25.01.2020

Кузьмина Ольга Алексеевна, аспирант кафедры романских языков

ФГБОУ ВО «Орловский государственный университет имени И.С. Тургенева»

302026, Россия, г. Орел, ул. Комсомольская, 95

E-mail: frkuzmina@mail.ru 


\title{
O.A. Kuzmina
}

\section{ON THE DESCRIPTION OF ARGOGRAPHIC SOURCES BASED ON THE NEWEST FRENCH YOUTH} ARGOT

\author{
DOI: $10.35634 / 2412-9534-2020-30-5-847-852$
}

The article is devoted to the vocabulary work of the French journalist Vincent Mongaillard, in which units of the French youth argot are inventoried. The purpose of the article is to analyze the thematic sections of the indicated argographic work, grouped on the basis of word-conversion techniques, on the one hand, and systematization of argot-attractive concepts, on the other hand. The lexicographic publication, created on the basis of the latest synchronous slice of specific vocabulary, is presented according to five criteria, such as the volume of the lexical fund, sources and word formation mechanisms, semantic dominants, synonymous series and metaphor. In the course of the study, systemic methods of argotic word-making were revealed. This confirms the frequency of using such a specific word-formation tool as verlan: argotisms formed through verlanization are included in all semantic macro fields presented in the work. Of the nonspecific mechanisms for replenishing the argot fund, metaphorics should be called first of all. Special attention is paid to the description of borrowings. The work provides numerous examples with translation into Russian.

Keywords: French youth argot, mechanisms of argot word creation, verlan, semantic dominant, language borrowings, synonymous series.

\section{REFERENCES}

1. Beregovskaya E.M. O sovremennom sostoianii russkoi sotsiodialektnoi leksikografii [On the current state of Russian social dialect lexicography] // Vosimye polivanovskiie chteniia [Eighth Polivanov Readings]. Slovo v tekste [The word in the text]. Leksikografiia kak istochnik informatsii dlia lingvisticheskikh issledovanii [Lexicography as a source of information for linguistic research]. Smolensk: Smolensk State University Press, 2007, pp. 215-222. (In Russian).

2. Beregovskaya E.M. Frantsuzskaya argotologuiia v Rossii: kollektivnaya monografiya [French argotology in Russia: collective monograph] Otv. red. E.M. Beregovskaya [Executive editor E.M. Beregovskaya]. Smolensk: Smolensk State University Press, 2011, 348 p. (In Russian).

3. Kuzmina O.A. Aktivnyye protsessy v sovremennom frantsuzskom molodozhnom argo [Active procecces in modern french youth argot] // Problemy lingvistiki, metodiki obucheniya inostrannym yazykam i literaturovedeniya v svete mezhkul'turnoy kommunikatsii. Materialy III Mezhdunarodnoy nauchno-prakticheskoy konferentsii. [Problems of linguistics, methodes of teaching foreign languages and literary criticism in the light of intercultural communication. Materials of the III International Scientific and Practical Conference]. Orel: Orel State University named after I.S. Turgenev, 2018. pp. 124-128. (In Russian).

4. Retinskaya T.I. Istochniki i mekhanizmy formirovaniya frantsuzskogo studencheskogo argo [Sources and mechanisms of the formation of the French student argot]. avtoref. diss. ... kand.filol.nauk [Diss. adstract of the cand. of philol. sciences]. Moscow, 2004. (In Russian).

5. Retinskaya T.I. Sociolingvisticheskij i funkcional'no-stilisticheskij analiz francuzskih professional'nyh argo [Sociolinguistic and functional-stylistic analysis of French professional argots]. Orel, 2011. 284 p. (In Russian).

6. Goudaillier J.-P. Comment tu tchatches ! Dictionnaire du français contemporain des cites - préf. Claude Hagège. Paris: Maisonneuve et Larose, 1998. 263 p

7. Goudaillier J.-P. La langue des cités // 25 ans d'écrits lexicographiques et argotologiques Hommage à Jean-Pierre Goudaillier pour son 65 anniversaire. Redaction Andrzej Napieralski. Lodz, 2014. 274 p.

8. Mongaillard V. Le petit livre de la tchatche. Décodeur de l'argot des cités. Paris. Editions First-Gründ, 2013.

Received 25.01.2020

Kuzmina O.A., postgraduate student at Department of Romance Philology

Oryol State University named after I.S. Turgenev

Komsomolskaya st., 95, Oryol, Russia, 302026

E-mail: frkuzmina@mail.ru 